\title{
Influence of Hf content on structure and electric properties of PHT thin films with self-buffered layer by PLD
}

\author{
Junfeng Li ${ }^{*}$ Jun Zhu, Zhipeng Wu, Wenbo Luo \\ State Key Laboratory of Electronic Thin Films and Integrated Devices, University of Electronics \\ Science and Technology of China, Chengdu 610054, People's Republic of China
}

\begin{abstract}
Three components of lead hafnate titanate $\left(\mathrm{PbHf}_{\mathrm{x}} \mathrm{Ti}_{1-\mathrm{x}} \mathrm{O}_{3}, \mathrm{PHT}\right)$ thin films have been fabricated by pulsed laser deposition (PLD) on the $\mathrm{Pt}$ $(111) / \mathrm{Ti} / \mathrm{SiO}_{2} / \mathrm{Si}(100)$ substrates. In order to reduce the mismatch between the thin films and substrates, low temperature self-buffered layer is adopted. The effects of Hf content on structure and electric properties of PHT thin films have been investigated. The PHT near the MPB $(x=0.48)$ shows the highest remnant polarization $\left(2 \mathrm{Pr}=93.23 \mu \mathrm{C} / \mathrm{cm}^{2}\right)$ and capacitance, even if its leakage current is a little worse than others. It should be noticed that the PHT ferroelectric films have a good performance after $2.15 \times 10^{10}$ fatigue reversals, which indicates that PHT films as a promising material can be applied in ferromagnetic random access memory (FRAM).
\end{abstract}

Keywords Lead hafnate titanate; morphotropic phase boundary; ferroelectric thin film; pulsed-laser deposition (PLD); remnant polarization

*Corresponding author. E-mail address: Lijunfeng0827@ outlook.com 


\section{Introduction}

Ferroelectric thin films with perovskite structure attract much attention for their fundamental properties and device applications, such as nonvolatile ferroelectric random access memory (NVFRAM), infrared detectors, sensors and actuators, ferroelectric field-effect transistors. Lead zirconate titanate $\left(\mathrm{PbZr}_{\mathrm{x}} \mathrm{Ti}_{1-\mathrm{x}} \mathrm{O}_{3}, \mathrm{PZT}\right)$ is one of the important ferroelectric materials owing to its good electrical properties. In the previous studies of PZT, many research groups made the effort to find the morphotropic phase boundary (MPB) as a result of its unique electrical properties and structure. The PZT phase diagram as accepted which is determined by Jaffe et al. [1] implies that MPB occurs around $x=0.52$. Mishra et al. [2] showed the electromechanical and dielectric response of PZT with $x=0.525$ is maximum, and, the maximum electromechanical response has been contributed [3] to the coexistence of tetragonal and rhombohedral phases around MPB. However, ferroelectric capacitors undergoing repeated switching (fatigue) tends to lose available remnant polarization. Improving the fatigue characteristics becomes a stringent problem. Watanabe et al. [4] found that the A-site or B-site substitution in BIT have received excellent fatigue properties. Schorn et al. [5] reported $\mathrm{Hf}^{4+}$ substituting for $\mathrm{Zr}^{4+}$ in PZT revealed a nice ferroelectric behavior and better fatigue performance. Lead hafnate titanate $\left(\mathrm{PbHf}_{\mathrm{x}} \mathrm{Ti}_{1-\mathrm{x}} \mathrm{O}_{3}\right.$, PHT), as a new kind of material, seems to be more suitable for FRAM 
application. Compared with PZT, the component of MPB in PHT proved to be very similar. Jaffe et al. [1] have already reported both rhombohedral and tetragonal phase were observed in the range of $x=0.475-0.500$. Frantti et al. [6] found that PHT around $x=0.50$ contained both monoclinic and rhombohedral phase. Sawai et al. [7] found that there existed a structure distortion from tetragonal symmetry in PHT near $\mathrm{x}=0.50$. Bedoya et al. [8] found that $\mathrm{Pb}_{0.94} \mathrm{Sr}_{0.06} \mathrm{Hf}_{0.49} \mathrm{Ti}_{0.51} \mathrm{O}_{3}$ exhibits the best properties.

Several researches showed that the structural and thermal mismatch between the thin films and substrates has bad impact on the performance of ferroelectric capacitor [9]. Wu et al. [10] have put forward an idea that adopting low temperature self-buffered layer to reduce the mismatch and influence the preferred orientation of $\mathrm{Ba}_{0.65} \mathrm{Sr}_{0.35} \mathrm{TiO}_{3}$. In the previous study, our research team members Lin et al. [11] have fabricated the $\mathrm{PbHf}_{0.30} \mathrm{Ti}_{0.70} \mathrm{O}_{3}$ films with tetragonal structure successfully by using low temperature self-buffered layer. It is found that the low temperature selfbuffer layer not only can improve the microstructure, but enhance the electric properties. In this paper, $\mathrm{PbHf}_{0.48} \mathrm{Ti}_{0.52} \mathrm{O}_{3}$ films were prepared for its component near the MPB. To make a comparison with $\mathrm{PbHf}_{0.48} \mathrm{Ti}_{0.52} \mathrm{O}_{3}$, $\mathrm{PbHf}_{0.52} \mathrm{Ti}_{0.48} \mathrm{O}_{3}$ and $\mathrm{PbHf}_{0.70} \mathrm{Ti}_{0.30} \mathrm{O}_{3}$ films were also made. To characterize its ferroelectric behavior and electrical properties, PHT was made as a thin film capacitor. We adopted the low temperature self- 
buffered layer to fabricate PHT films on the platinum coated silicon substrates and made an exploration on the electrical properties. The results reveal that the $\mathrm{PbHf}_{0.48} \mathrm{Ti}_{0.52} \mathrm{O}_{3}$ films show the highest remnant polarization and largest capacitance, but the highest leakage current. On the other hand, the fatigue measurements indicate that PHT films have better prospects development in FRAM.

\section{Experimental}

Pulsed laser deposition (PLD) has been widely used to produce the oriented ferroelectric thin films with its high reliability. Three components of PHT films were grown through the use of $\mathrm{KrF}$ excimer laser (Lambda Physik Complex 201, $248 \mathrm{~nm}$ ). The PHT ceramics target was prepared by a conventional solid-state reaction technique from 99.99\% pure powders $\left(\mathrm{Pb}_{3} \mathrm{O}_{4}, \mathrm{TiO}_{2}\right.$ and $\left.\mathrm{HfO}_{2}\right)$. To compensate the volatilization of $\mathrm{Pb}$ during the target of sintering and films deposition process, a wt.10\% additional $\mathrm{Pb}_{3} \mathrm{O}_{4}$ is essential. Followed by the acetone, ethanol, and de-ionized water cleaning to substrates, substrates were prepared for the deposition of films. In the follow-up experiments, the self-buffered layer was grown at $300^{\circ} \mathrm{C}$ with the oxygen pressure of $20 \mathrm{~Pa}$ and the thickness was about 20nm. Then, the PHT film was deposited on the self-buffered layer at $600^{\circ} \mathrm{C}$ for $130 \mathrm{~nm}$. The annealing temperature was $600^{\circ} \mathrm{C}$ for $30 \mathrm{~min}$.

The microstructures were measured by Bede D1 X-ray diffraction 
(XRD). For the purpose of testing the performance of films, the metal/ferroelectric/metal (MFM) structure was applied. The nickel/gold top electrodes were chosen deposited by electron beam evaporation, whose areas are about $2.5 \times 10^{-4} \mathrm{~cm}^{2}$. The electric performance testing structure of PHT films was shown in Fig.1. The polarization-electric field (P-E) and fatigue curve were carried out by a Radiant Precision LC (RT2000) material analyzer. The capacitance-voltage(C-V) and leakagevoltage (I-V) tests were performed by Agilent 4294A and Agilent 4156C.

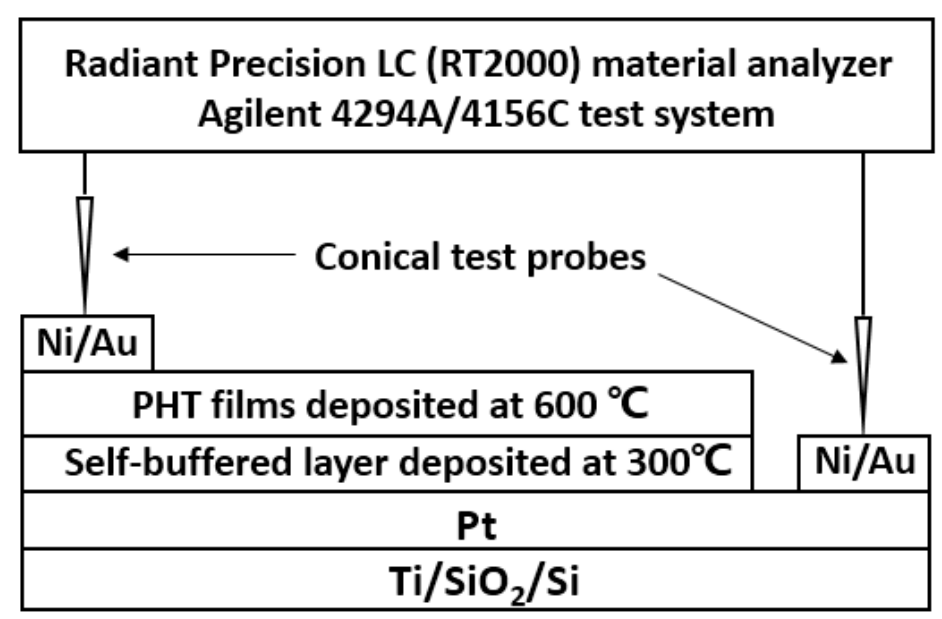

Fig.1 The test structure of $\mathrm{PbHf}_{\mathrm{x}} \mathrm{Ti}_{1-\mathrm{x}} \mathrm{O}_{3}$ films with self-buffered layer.

\section{Results and discussions}

\subsection{Structure Analysis}

Fig.2 shows the XRD patterns of the $\mathrm{PbHf}_{\mathrm{x}} \mathrm{Ti}_{1-\mathrm{x}} \mathrm{O}_{3}$ thin films. As we know, PHT has the similar structure with PZT [1]. The tetragonal (T) and rhombohedral $(\mathrm{R})$ phases of PZT are distinguishable on XRD since the 200/020/002 set of reflections form a doublet and singlet for T and R phases respectively [2]. The XRD diagram of $\mathrm{PbHf}_{0.48} \mathrm{Ti}_{0.52} \mathrm{O}_{3}$ proves the 
coexistence of two phases. With increasing $\mathrm{x}$ from 0.48 to 0.52 , the $\mathrm{T}$ phase of disappears, which means that the structure of PHT changes from two phases to $\mathrm{R}$ phase. Along with the $\mathrm{x}$ continuously increasing to 0.7 , the structure is the similar as $\mathrm{x}=0.52$.

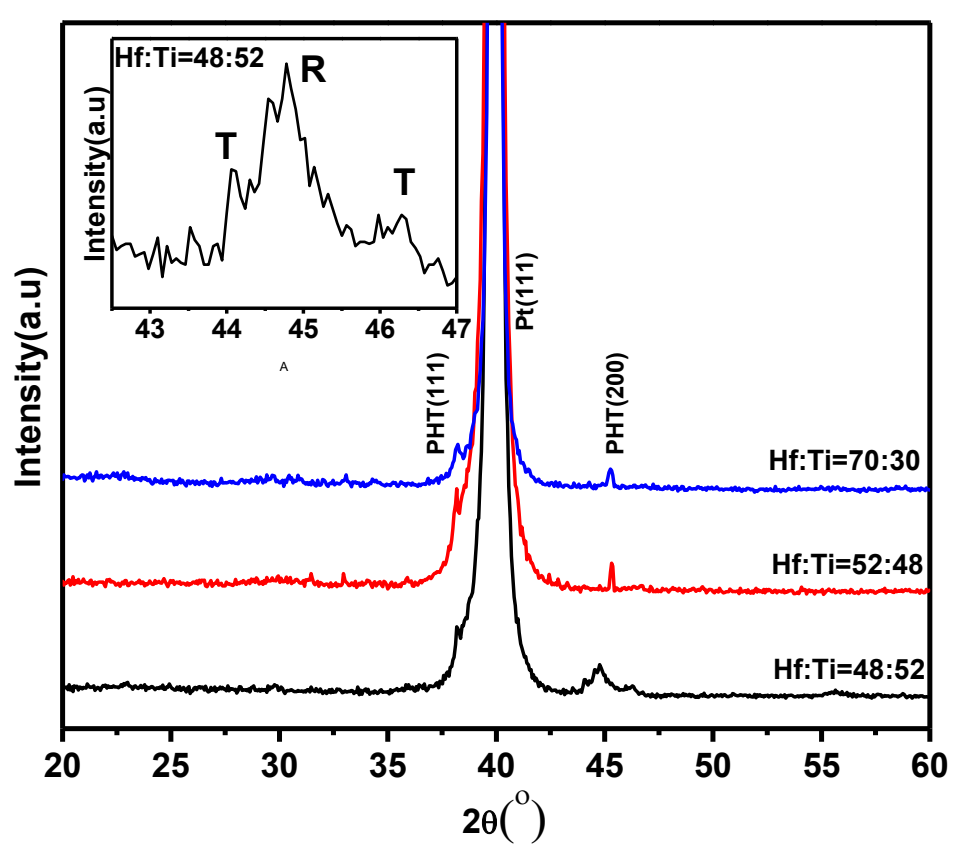

Fig.2 XRD patterns of $\mathrm{PbHf}_{\mathrm{x}} \mathrm{Ti}_{1-\mathrm{x}} \mathrm{O}_{3}$ thin films with self-buffered layer for $\mathrm{x}=0.48,0.52$ and 0.70 .

\subsection{Electric Properties}

Ferroelectric P-E hysteresis loops were tested as shown in Fig.3. The test frequency was about $100 \mathrm{~Hz}$. It can be seen that PHT films with different components reveal individual $\mathrm{P}-\mathrm{E}$ hysteretic behaviors. The $\mathrm{PbHf}_{0.48} \mathrm{Ti}_{0.52} \mathrm{O}_{3}$ thin film have the largest remnant polarization $\left(2 \operatorname{Pr}=93.23 \mu \mathrm{C} / \mathrm{cm}^{2}\right)$. Lin et al. [11] have showed the highest remnant polarization of $\mathrm{PbHf}_{0.30} \mathrm{Ti}_{0.70} \mathrm{O}_{3}$ films is about $63 \mu \mathrm{C} / \mathrm{cm}^{2}$. It is also 
reported that the $2 \mathrm{Pr}$ of $\mathrm{BTH}$ and PZT films are about $45.7 \mu \mathrm{C} / \mathrm{cm}^{2}$ and $69 \mu \mathrm{C} / \mathrm{cm}^{2}$, respectively $[12,13]$. Compared with these mainstream ferroelectric films, $\mathrm{PbHf}_{0.48} \mathrm{Ti}_{0.52} \mathrm{O}_{3}$ films reveal better ferroelectric performance. As shown in Fig.4, the $\mathrm{PbHf}_{0.48} \mathrm{Ti}_{0.52} \mathrm{O}_{3}$ films, whose component near MPB, reveal best ferroelectric performance. At MPB region, the polarization directions of electric domain is more than other regions and are easy to be polarized under the force of electric field. With increasing $\mathrm{x}$ from $\mathrm{x}=0.48$ to 0.70 , the remnant polarization decreases.

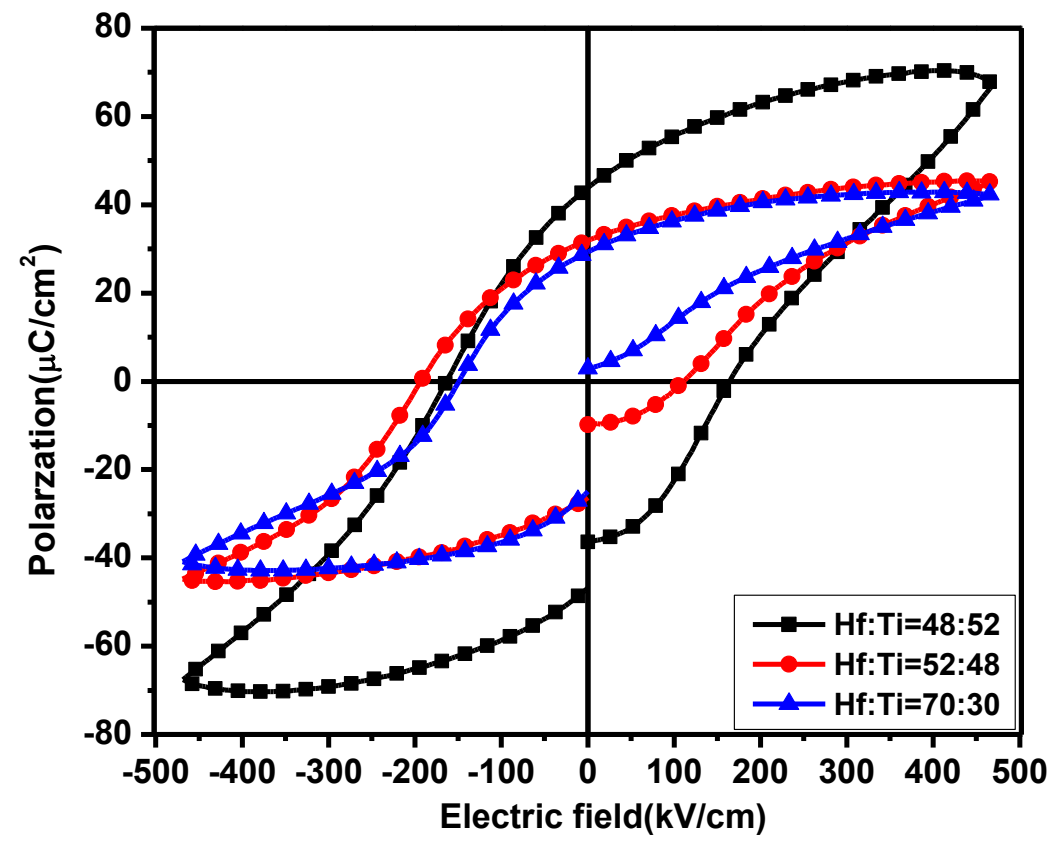

Fig.3 Ferroelectric P-E hysteresis of $\mathrm{PbHf}_{\mathrm{x}} \mathrm{Ti}_{1-\mathrm{x}} \mathrm{O}_{3}$ films for $\mathrm{x}=0.48,0.52$ and 0.70 . 


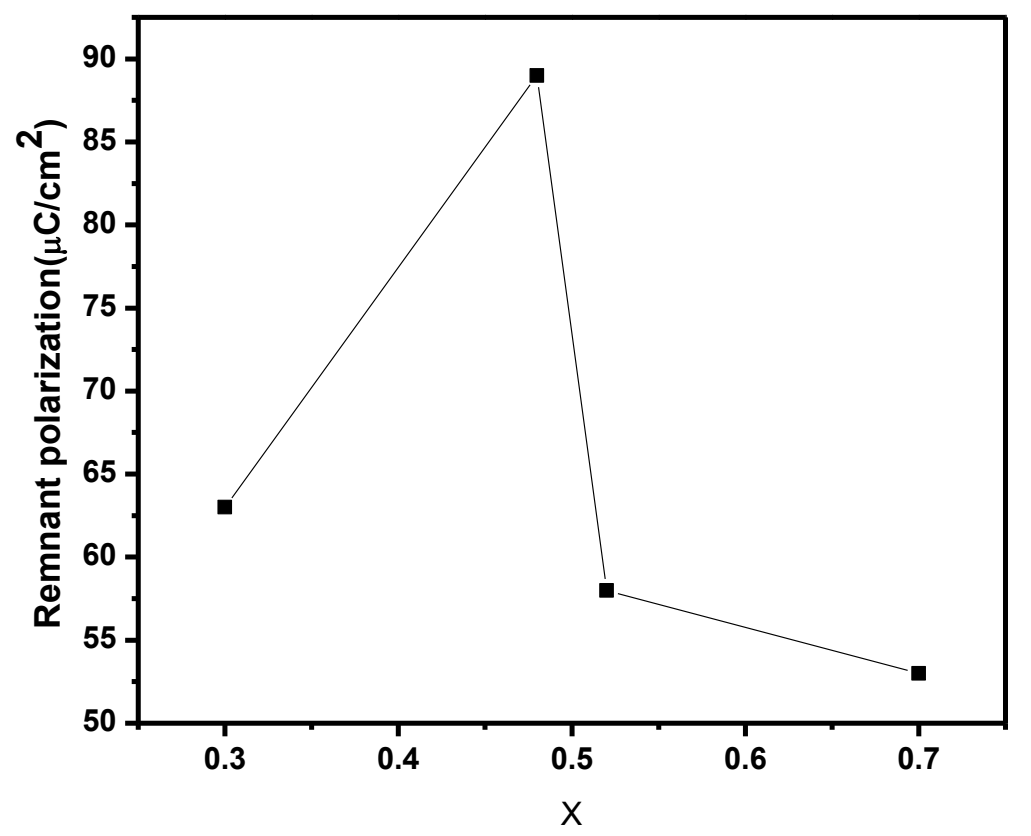

Fig.4 Variation of $2 \mathrm{Pr}$ with component $(\mathrm{x})$ of $\mathrm{PbHf}_{\mathrm{x}} \mathrm{Ti}_{1-\mathrm{x}} \mathrm{O}_{3}$ thin films.

The capacitance and the leakage current of films were measured as shown in Fig.5 and Fig.6. Capacitance is an important indicator for relating to the dielectric performance of film. The capacitance versus bias voltage was measured at room temperature and the test frequency was about 1MHz. As shown in Fig.5, the $\mathrm{PbHf}_{0.48} \mathrm{Ti}_{0.52} \mathrm{O}_{3}$ films appear the largest capacitance in all simples, which indicates the highest dielectric constant. This phenomenon is similar with the PZT near the MPB [2]. In previous research, the capacitance of $\mathrm{PbZr}_{0.52} \mathrm{Ti}_{0.48} \mathrm{O}_{3}$ films measured at 1 $\mathrm{KHz}$ is about 760pF [14]. Fig.6 shows the current density characteristics of PHT films. The PHT films with $\mathrm{x}=0.48$ have worse insulation performance, compared with other PHT films. This behave can be understand by considering the coexistence of two phases makes the 
number of grain boundary and defects increase. As we know, the leakage current density is closely connected with the defects. The more the number of defects, the higher the current density. The loops of the films seen to be asymmetric as a result of the electrodes, test equipment and an internal electric filed in the thin films.

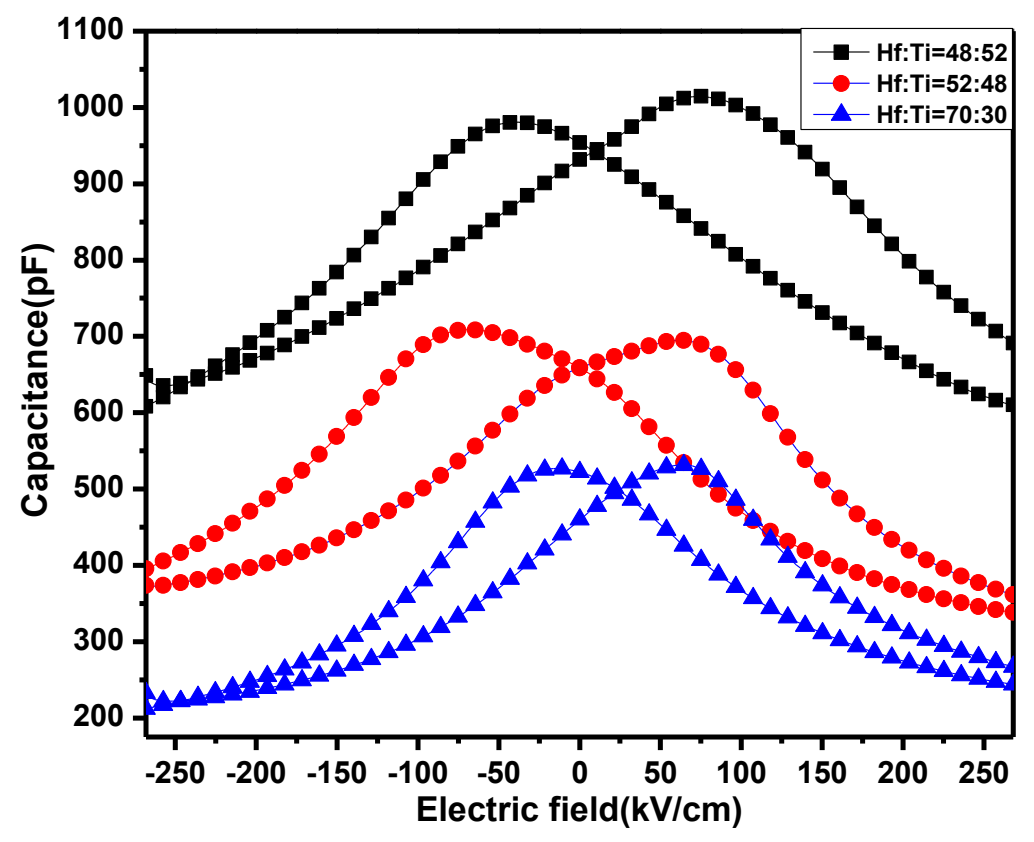

Fig.5.The capacitance versus voltage curves of the $\mathrm{PbHf}_{\mathrm{x}} \mathrm{Ti}_{1-\mathrm{x}} \mathrm{O}_{3}$ thin films for $\mathrm{x}=0.48,0.52$ and 0.70 . 


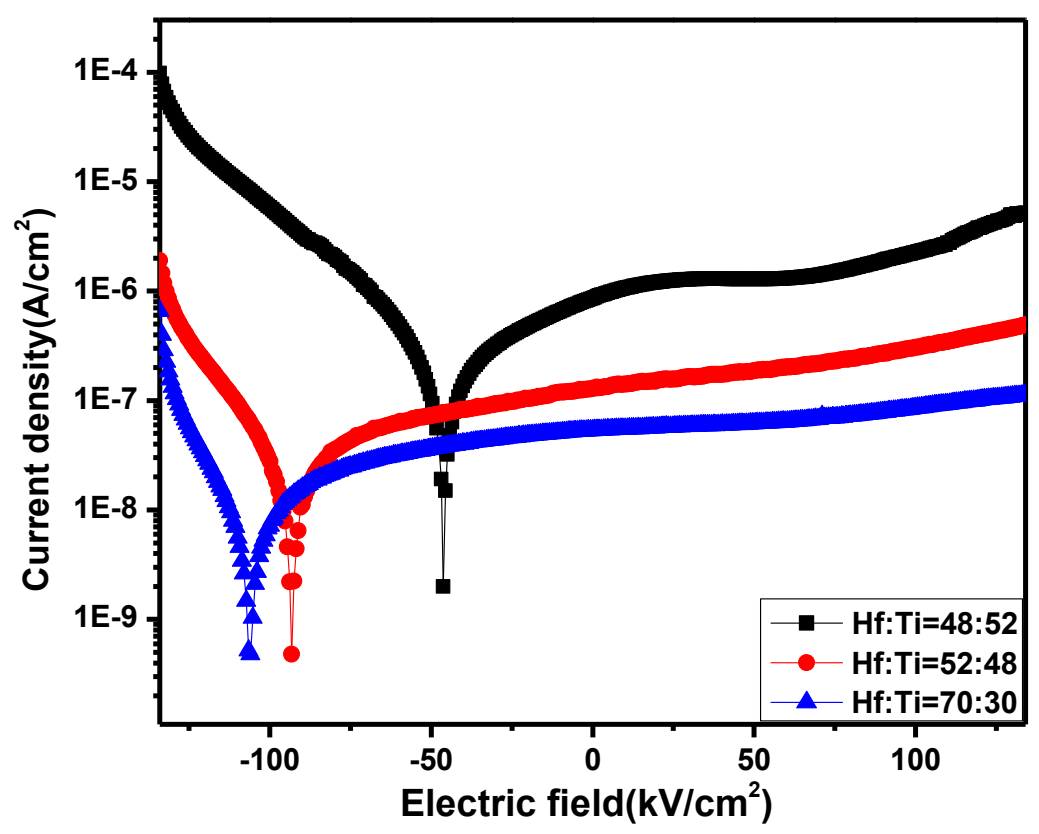

Fig.6. Current density of $\mathrm{PbHf}_{\mathrm{x}} \mathrm{Ti}_{1-\mathrm{x}} \mathrm{O}_{3}$ films for $\mathrm{x}=0.48,0.52$ and 0.70 .

The reliability of the ferroelectric films is another important factor of the application. Ferroelectric fatigue is much fatal for the electric apparatus based on the switchable polarization, such as NVFRAM. The fatigue properties of some PHT films were investigated in Fig.7. These measurements were processed in a switching electric field of $\pm 250 \mathrm{kV} / \mathrm{cm}$. As the result shows, after $2.15 \times 10^{10}$ switching cycles, the remnant polarization (2Pr) of the $\mathrm{PbHf}_{0.52} \mathrm{Ti}_{0.48} \mathrm{O}_{3}$ and $\mathrm{PbHf}_{0.70} \mathrm{Ti}_{0.30} \mathrm{O}_{3}$ films almost maintain the initial value. On the contrary, the $\mathrm{PbHf}_{0.48} \mathrm{Ti}_{0.52} \mathrm{O}_{3}$ films show a little bad fatigue performance for $15 \%$ degradation. In the previous studies, after $10^{9}$ switching cycles, BTH and PZT thin films show a significant degradation of polarization (generally greater than or equal to $20 \%)[5,15]$. It was assumed that the fatigue is mainly due to the pinning 
of domain walls by space charge or charged point defects near $\mathrm{Pt}$ electrodes [16]. Furthermore, the insulation performance of films, which often relates to the defects, has an impact on the fatigue. As discussed previously, the coexistence of two phases induce the number of defects increased. This is the reason why the fatigue performance of $\mathrm{PbHf}_{0.48} \mathrm{Ti}_{0.52} \mathrm{O}_{3}$ is a bit poor compared to other PHT films.

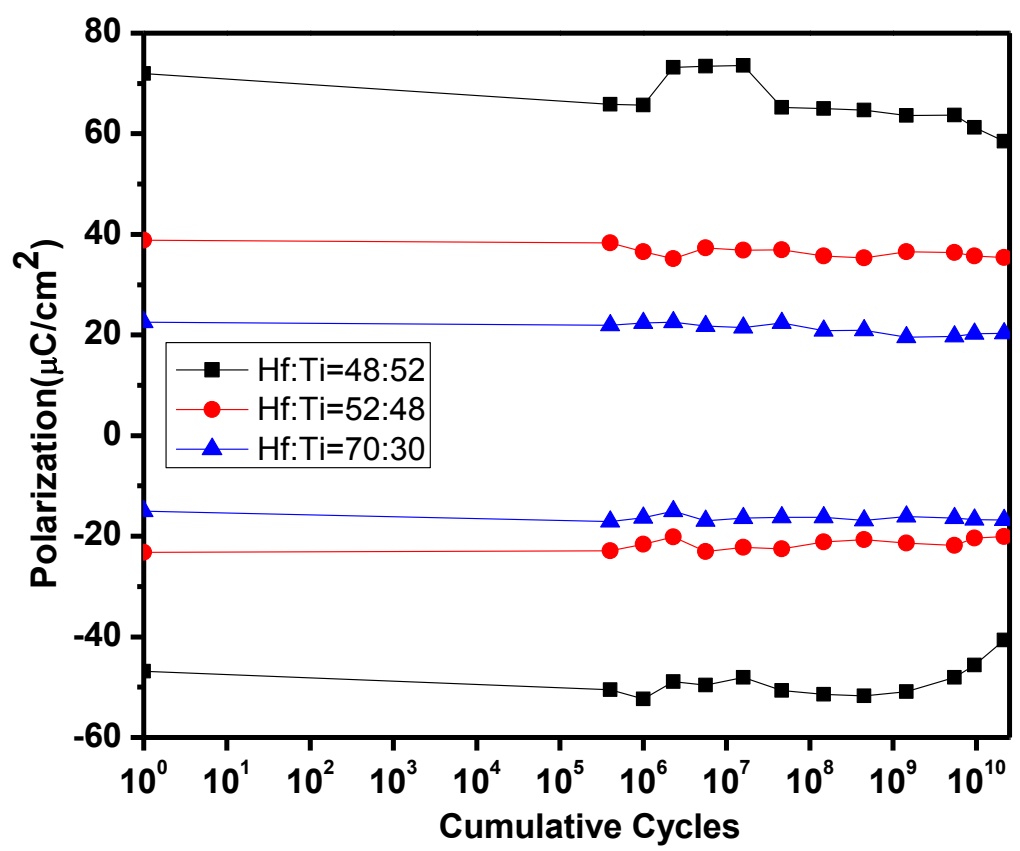

Fig.7 The fatigue curves of PHT thin films for $\mathrm{x}=0.48,0.52$ and 0.70 .

From all the above results, it can been seen obviously that the $\mathrm{PbHf}_{0.48} \mathrm{Ti}_{0.52} \mathrm{O}_{3}$ films near MPB show highest remnant polarization and capacitance, even if its leakage current and fatigue performances are little worse than other components. The cause of this phenomenon is the coexistence of two phases. As the structure of PHT changes to single phase, the ferroelectric and capacitance properties become worse. The 
fatigue tests show that PHT has very good application prospects in FRAM.

\section{Conclusion}

In summary, three components of PHT thin films were fabricated on the $\mathrm{Pt}(111) / \mathrm{Ti} / \mathrm{SiO}_{2} / \mathrm{Si}(100)$ substrates successfully by PLD and their properties have been tested. Compared with other components of PHT, the $\mathrm{PbHf}_{0.48} \mathrm{Ti}_{0.52} \mathrm{O}_{3}$, whose component is close to the phase boundary, reveals better ferroelectric and capacitance properties, though its leakage current and fatigue performances are a bit poor. Furthermore, the PHT films show nice fatigue after $2.15 \times 10^{10}$ switching cycles, which indicate PHT films have a vast practical future in FRAM.

\section{Acknowledgements}

This work was supported by the Supporting Project from the National Science Foundation of China (Nos. 51372030).

\section{References}

[1] Jaffe, B., Roth, R. S. and Marzullo, S., Properties of piezoelectric ceramics in the solid solution series lead titanate-lead zirconate-lead oxide: tin oxide and lead titanate-lead hafnate, J. Res. Nat. Bur. Stds, $55(1955)$ 239-254.

[2] S.K. Mishra, D. Pandey, A.P. Singh, Effect of phase coexistence at morphotropic phase boundary on the properties of $\mathrm{Pb}\left(\mathrm{Zr}_{\mathrm{x}} \mathrm{Ti}_{1-\mathrm{x}}\right) \mathrm{O}_{3}$ 
ceramics, APPL PHYS LETT, 69(1996) 1707.

[3] Carl, K., and K. H. Härdtl, On the origin of the maximum in the electromechanical activity in $\mathrm{Pb}\left(\mathrm{Zr}_{\mathrm{x}} \mathrm{Ti}_{1-\mathrm{x}}\right) \mathrm{O}_{3}$ ceramies near the morphotropic phase boundary, Physica Status Solidi, 8(1971) 87-98.

[4] T. Watanabe, H. Funakubo, M. Osada, Y. Noguchi, M. Miyayama, Effect of cosubstitution of $\mathrm{La}$ and $\mathrm{V}$ in $\mathrm{Bi}_{4} \mathrm{Ti}_{3} \mathrm{O}_{12}$ thin films on the lowtemperature deposition, APPL PHYS LETT, 80(2002) 100.

[5] P.J. Schorn, T. Schneller, U. Bottger, R. Waser, Characterization of Chemical Solution Deposition-Derived Lead Hafnate Titanate Thin Films, J. AM CERAM SOC, 88(2005) 1312-1314.

[6] J. Frantti, Y. Fujioka, S. E5riksson, S. Hull, M. Kakihana, Neutron Powder Diffraction Study of $\mathrm{Pb}\left(\mathrm{Hf}_{\mathrm{x}} \mathrm{Ti}_{1-\mathrm{x}}\right) \mathrm{O}_{3}$ Ceramics $(0.10 \leq \mathrm{x} \leq 0.50)$, INORG. CHEM, 44(2005) 9267-9278.

[7] S. SAWAI, H. TAKEUCHI, N. OOHATA, Lattice constants and phase transition of $\mathrm{Pb}\left(\mathrm{Hf}_{\mathrm{x}} \mathrm{Ti}_{1-\mathrm{x}}\right) \mathrm{O}_{3}$. Integrated Ferroelectrics, 100(2008) 123131.

[8]C. Beboya, Ch.Muller, A. Kowaiski, E. Nigrelli, M.Roubin, Investigation of the morphotropic region in the Sr-doped lead hafnatetitanate solid solution $\mathrm{Pb}_{0.94} \mathrm{Sr}_{0.06} \mathrm{Hf}_{0.49} \mathrm{Ti}_{0.51} \mathrm{O}_{3}$. Journal of materials science: Materisls in electronics, 12(2001)543-550.

[9] Chin-Chi Cheng, San-Lin Young, Hone-Zern Chen, Sen-Yeu Yang, Substrate effect on characteristics of $\mathrm{Pb}\left(\mathrm{Zr}_{\mathrm{x}} \mathrm{Ti}_{1-\mathrm{x}}\right) \mathrm{O}_{3}$ (PZT) film. 
Integrated Ferroelectrics, 150(2014) 51-58.

[10] C.G. Wu, Y.R. Li, J. Zhu, X.Z. Liu, W.L. Zhang, Great enhancement of pyroelectric properties for $\mathrm{Ba}_{0.65} \mathrm{Sr}_{0.35} \mathrm{TiO}_{3}$ films on $\mathrm{Pt}-\mathrm{Si}$ substrates by inserting a self-buffered layer, J. APPL PHYS, 105(2009) 44107.

[11]Y.L.Lin, J.Zhu, Z.P.Wu, W.B.Luo, Enhanced ferroelectric properties of (111) oriented $\mathrm{Pb}\left(\mathrm{Hf}_{0.3} \mathrm{Ti}_{0.7}\right) \mathrm{O}_{3}$ thin films deposited using self-buffered layer, Journal of Alloys and Compounds, 627(2015) 182-185.

[12]X.P.Wang, J.Zhu, W.B.Luo, Y.Zhang, Y.R.Li, Enhanced ferroelectric properties of Hf-doped bismuth titanate thin films on STO (111) substrates, Journal of Applied Physics, 104(2008) 074112.

[13]Junhong Li, Wei Ren, Chenghao Wang, Mengwei Liu, Guoxiang Fan, Micro-patterning of PZT thick films by lift-off using $\mathrm{ZnO}$ as a sacrificial layer, Ceramics International, 41(2015) 7325-7328.

[14] V Trtk, M Jelinek and E B Kluenkov, A study of laser-deposited PZT, PLZT, PMN and YBCO thin films, J. Phys. D: Appl. Phys, 27(1994) 1544-1547.

[15]Wei Li, Jun Gu, Chunhua Song, Dong Su, and Jinsong Zhu, B-site doping effect on ferroelectric property of bismuth titanate ceramic, Journal of Applied Physics, 98(2005) 114104.

[16] Feng Yan, Peng Bao, Helen L.W. Chan, Chung-Loong Choy, Yening Wang, The grain size effect of $\mathrm{Pb}\left(\mathrm{Zr}_{0.3} \mathrm{Ti}_{0.7}\right) \mathrm{O}_{3}$ thin films, Thin Solid Films, 406(2002) 282-285. 